This is an electronic reprint of the original article. This reprint may differ from the original in pagination and typographic detail.

Author(s): Nauha, Elisa; Nissinen, Maija

Title: $\quad$ Co-crystals of an agrochemical active - A pyridine-amine synthon for a thioamide group

Year: $\quad 2011$

Version:

Please cite the original version:

Nauha, E., \& Nissinen, M. (2011). Co-crystals of an agrochemical active - A pyridineamine synthon for a thioamide group. Journal of Molecular Structure, 1006(1-3), 566-569. https://doi.org/10.1016/j.molstruc.2011.10.004

All material supplied via JYX is protected by copyright and other intellectual property rights, and duplication or sale of all or part of any of the repository collections is not permitted, except that material may be duplicated by you for your research use or educational purposes in electronic or print form. You must obtain permission for any other use. Electronic or print copies may not be offered, whether for sale or otherwise to anyone who is not an authorised user. 


\title{
Co-crystals of an agrochemical active - a pyridine-amine synthon for a thioamide group
}

\author{
E. Nauha and M. Nissinen* \\ Department of Chemistry, Nanoscience Center, University of Jyväskylä, P.O.Box 35, FIN-40014 University \\ of Jyväskylä, Finland, Fax: +35814 260 4756; Tel: +35850 428 0804; E-mail: maija.nissinen@jyu.fi
}

\begin{abstract}
Five novel co-crystals of thiophanate-ethyl (TE), an agrochemical active, with di(2-pyridyl)ketone (1), 2benzoylpyridine (2), 3-benzoylpyridine (3), 4-phenylpyridine (4) and biphenyl (5) were found and crystal structures of four of them (TE1-TE3, TE5) solved by single crystal X-ray diffraction. Three of the cocrystals (TE1-TE3) form by way of a reliable pyridine-amine hydrogen bond synthon and one (TE5) because of close packing effects. The fifth co-crystal was identified by X-ray powder diffraction. The work demonstrates the usage of a reliable supramolecular synthon for crystal engineering, while concurrently reminds that the close packing of even very similar molecules cannot be fully predicted.
\end{abstract}

Keywords: co-crystal, synthon, agrochemical, thioamide, X-ray diffraction

\section{Introduction}

Co-crystal, i.e. multi-component molecular crystals, are of an interest to pharmaceutical and agrochemical companies as possible new and improved dosage forms.[1] The primary method of designing new co-crystals is the use of reliable supramolecular synthons[2], which are mainly composed of hydrogen bonds. Active ingredients often have many functional groups capable of hydrogen bonding, which makes this approach somewhat challenging.

We have previously investigated the polymorphism and solvate formation of an agrochemical active, thiophanate-ethyl (TE, diethyl 4,4'-(o-phenylene)bis(3-thioallophanate) (Scheme 1), which was found to have four polymorphs and seven solvate forms [3]. TE and an analogous thiophanate-methyl[4] both have a hydrogen bonded pyridine solvate. They have also been found to make co-crystals[5] with 2,2'-bipyridine, 4,4'-bipyridine and 1,2-bis(4-pyridyl)ethane. Inspired by the success, we wanted to investigate whether the $\mathrm{N}-\mathrm{H} \cdot \cdots \mathrm{N}$ hydrogen bond could be used further for co-crystal design and screened with a series of azaheterocycles (1-4) (Scheme 1) containing a pyridine moiety. Biphenyl (5) (Scheme 1) was selected as a comparison to investigate if it would take the place of 2,2'-bipyridine and make an arrangement also seen in several isomorphous solvates of TE. 


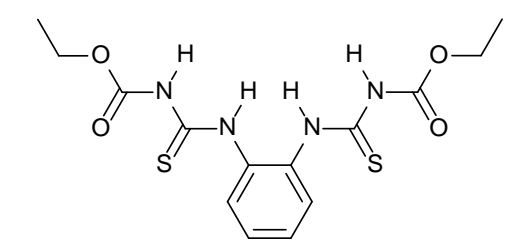

(TE)<smiles>O=C(c1ccccn1)c1ccccn1</smiles>

(1)<smiles>O=C(c1ccccc1)c1ccccn1</smiles>

(2)<smiles>O=C(c1ccccc1)c1cccnc1</smiles>

(3)<smiles>c1ccc(-c2ccncc2)cc1</smiles>

$(4)$<smiles>c1ccc(-c2ccccc2)cc1</smiles>

(5)

Scheme 1. Molecular structures of TE, di(2-pyridyl)ketone (1), 2-benzoylpyridine (2), 3-benzoylpyridine (3), 4phenylpyridine (4) and biphenyl (5)

Piotrowska et al. [6] found dithiooxamide, a simpler compound that has some of the same functionalities as TE and TM, to be a convenient substrate for construction of two component supramolecular structures with azaheterocycles. Ellis et al. [7] used the same approach for a number of thiocarbamide derivatives and found that they formed many 2:1 co-crystals with bipyridine-type molecules. As agrochemical and pharmaceutical actives are often quite complicated molecules with a number of functionalities, we wanted to see if the pyridine-amine synthon would work well for such systems.

\section{Experimental}

\subsection{Slurries and crystallizations}

TE (99\% Chem Service), biphenyl (99\% Merck), 4-phenylpyridine (97\% Aldrich), 2-benzoylpyridine (99\% Aldrich), 3-benzoylpyridine (97\% Aldrich), di(2-pyridyl)ketone (99\% Aldrich), distilled water and solvents of analytical purity (min 99\%) were used in the crystallization and slurry experiments. Screening was started with slurries (50 mg of TE and 25-150 mg of azaheterocycle/biphenyl depending on solubility and starting from a ratio of 1:1) in $2 \mathrm{ml}$ of 1:4 MeCN:water, which were mixed for one month in RT. Evaporation crystallizations of the slurry samples in 1:1 MeCN:water or in MeCN (in the case of 2-benzoylpyridine) resulted in single crystals suitable for crystal structure determination for samples of TE with (1), (2), (3) and (5).

\subsection{Powder X-ray diffraction}

For powder X-ray diffraction (PXRD) analysis the original compounds and the slurries were pressed to a zero background silicon plate and measured on a PANalytical X'Pert Pro system in reflection mode with $\mathrm{CuK} \alpha 1$-radiation. A $2 \theta$-angle range of $3-35^{\circ}$ and a step time of $60 \mathrm{~s}$ were used with step resolution of $0.0167^{\circ}$. Figures were drawn with X’Pert HighScore Plus [8]. 


\subsection{Single crystal X-ray diffraction}

The single crystal X-ray diffraction data was collected on Nonius Kappa CCD-diffractometer with Apex II detector at $173 \mathrm{~K}$, using graphite-monochromated $\mathrm{CuK} \alpha$ radiation $(\lambda=1.54178 \AA$ ). Absorption correction was performed with Denzo-SMN 1997 [9]. The structures were solved using direct methods, refined, and expanded by using Fourier techniques with the SHELX-97 software package [10]. All non-hydrogen atoms were refined anisotropically. Hydrogen atoms were placed in idealized positions or found from the electron density map (hydrogen bonding N-H hydrogens), and included in structure factor calculations. The N-H hydrogen atoms found in the electron density map were restrained to a distance of $0.91 \AA$ for TE1 and TE2 to give the best fit to the X-ray data and to ensure stable refinement. Pictures of the structures were drawn with Mercury 2.4 [11]. Crystal data and refinement parameters are presented in Table 1 . To verify the identity of the isomorphic co-crystals, cross refinement of the differing $\mathrm{C} / \mathrm{N}$ in di(2-pyridyl)ketone and 2benzoylpyridine were done resulting in higher $\mathrm{R}$-values and too small/large ellipsoids.

Table 1. Crystal data and refinement parameters

\begin{tabular}{|c|c|c|c|c|}
\hline & TE1ekn035 & TE2ekn042 & TE3ekn033 & TE5ekn034 \\
\hline Chemical formula & $\begin{array}{l}\mathrm{C}_{14} \mathrm{H}_{18} \mathrm{~N}_{4} \mathrm{O}_{4} \mathrm{~S}_{2} \\
\mathrm{C}_{11} \mathrm{H}_{8} \mathrm{~N}_{2} \mathrm{O}\end{array}$ & $\begin{array}{l}\mathrm{C}_{14} \mathrm{H}_{18} \mathrm{~N}_{4} \mathrm{O}_{4} \mathrm{~S}_{2} \\
\mathrm{C}_{12} \mathrm{H}_{9} \mathrm{NO}\end{array}$ & $\begin{array}{l}\mathrm{C}_{14} \mathrm{H}_{18} \mathrm{~N}_{4} \mathrm{O}_{4} \mathrm{~S}_{2} \\
2\left(\mathrm{C}_{12} \mathrm{H}_{9} \mathrm{NO}\right)\end{array}$ & $\begin{array}{l}\mathrm{C}_{14} \mathrm{H}_{18} \mathrm{~N}_{4} \mathrm{O}_{4} \mathrm{~S}_{2} \\
0.5\left(\mathrm{C}_{12} \mathrm{H}_{10}\right)\end{array}$ \\
\hline$M_{\mathrm{r}}$ & 554.64 & 553.65 & 736.85 & 447.54 \\
\hline Crystal system & Monoclinic & Monoclinic & Monoclinic & Triclinic \\
\hline Space group & $P 2_{1} / c$ & $P 2_{1} / c$ & $P 2_{1} / c$ & $P-1$ \\
\hline Temperature (K) & 173 & 173 & 173 & 173 \\
\hline$a(\AA)$ & $12.7612(7)$ & $12.8497(5)$ & $10.4541(4)$ & $8.8861(1)$ \\
\hline$b(\AA)$ & $8.3916(4)$ & $8.5996(3)$ & $26.8015(11)$ & $10.0077(2)$ \\
\hline$c(\AA)$ & $26.3679(14)$ & $26.0775(9)$ & $13.1925(6)$ & $12.7746(3)$ \\
\hline$\alpha\left({ }^{\circ}\right)$ & 90 & 90 & 90 & $85.098(2)$ \\
\hline$\beta\left(^{\circ}\right)$ & $112.022(3)$ & $112.182(2)$ & $102.607(2)$ & 78.793 (1) \\
\hline$\gamma\left({ }^{\circ}\right)$ & 90 & 90 & 90 & 79.930 (1) \\
\hline$V\left(\AA^{3}\right)$ & $2617.6(2)$ & $2668.4(2)$ & $3607.2(3)$ & $1095.65(4)$ \\
\hline$Z$ & 4 & 4 & 4 & 2 \\
\hline$\mu\left(\mathrm{mm}^{-1}\right)$ & 2.26 & 2.20 & 1.80 & 2.49 \\
\hline Crystal size (mm) & $0.15 \times 0.05 \times 0.05$ & $0.12 \times 0.10 \times 0.06$ & $0.30 \times 0.08 \times 0.06$ & $0.22 \times 0.22 \times 0.20$ \\
\hline$T_{\min }, T_{\max }$ & $0.728,0.896$ & $0.778,0.879$ & $0.614,0.900$ & $0.610,0.635$ \\
\hline 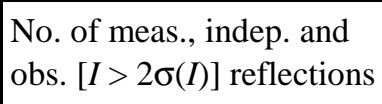 & $6507,4031,2035$ & $7725,4631,3414$ & $11459,6233,3761$ & $5449,3754,3396$ \\
\hline$R_{\mathrm{int}}$ & 0.137 & 0.069 & 0.107 & 0.085 \\
\hline$R\left[F^{2}>2 \sigma\left(F^{2}\right)\right], w R\left(F^{2}\right), S$ & $0.079,0.214,1.03$ & $0.050,0.126,1.05$ & $0.064,0.164,1.02$ & $0.046,0.126,1.03$ \\
\hline No. of reflections & 4031 & 4631 & 6233 & 3754 \\
\hline No. of parameters & 345 & 357 & 484 & 285 \\
\hline No. of restraints & 4 & 4 & 0 & 0 \\
\hline$\Delta \rho_{\max }, \Delta \rho_{\min }\left(\mathrm{e} \AA^{-3}\right)$ & $0.39,-0.36$ & $0.24,-0.29$ & $0.32,-0.28$ & $0.29,-0.28$ \\
\hline
\end{tabular}




\section{Results and discussion}

\subsection{Hydrogen bonded co-crystals}

The isomorphic di(2-pyridyl ketone) (TE1) and 2-benzoylpyridine (TE2) co-crystals have a ratio of 1:1 TE:(1)/(2). The structures exhibit a complicated array of single and bifurcated hydrogen bonds (Fig. 1), unlike in the other TE structures [3,5], where a pairing of two donors and acceptors is often seen. The two N$\mathrm{H}$ hydrogen atoms that participate in a S(6) intramolecular motif [12] are not further hydrogen bonded. However, the $\mathrm{C}=\mathrm{O}$ acceptors of the same motif are additionally involved in hydrogen bonding to adjacent bifurcated N-H donors. The C1,1(4) and C1,1(11) motifs starting from the bifurcated N-H donors combine to build double chains of TE molecules running in the direction of the crystallographic b-axis. When C-H donors are taken into account, one of the $\mathrm{C}=\mathrm{S}$ sulfurs and ether oxygen atoms also participate in hydrogen bonding within the TE chains. The azaheterocycles (1) and (2) are connected to one arm of TE with the pyridine-amine synthon. In addition, the $\mathrm{C}=\mathrm{O}$ in (1) and (2) have a weak hydrogen bond to the methyl groups of TE of the adjacent chains. In TE1 the other pyridine nitrogen of (1) is, however, not involved in hydrogen bonding.

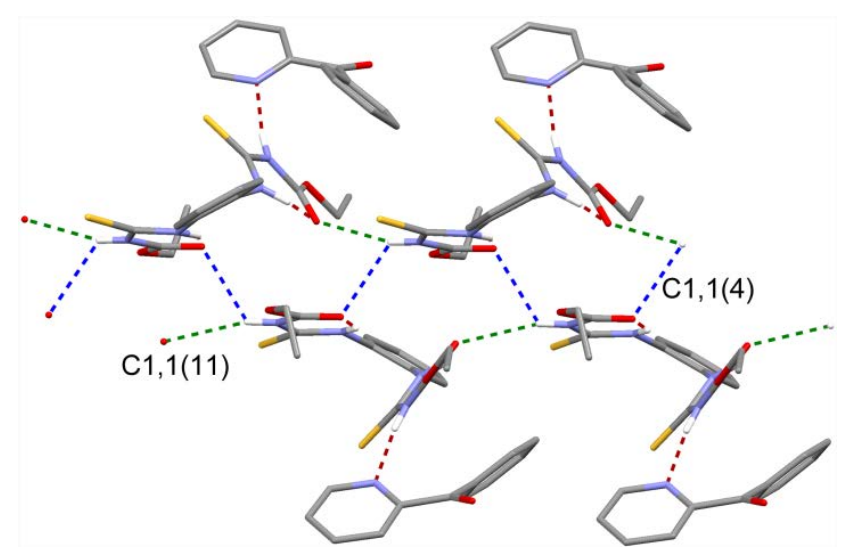

Figure 1. Hydrogen bonding chains in the di(2-pyridyl ketone) (TE1) and 2-benzoylpyridine (TE2) co-crystals with C$\mathrm{H}$ hydrogen atoms removed for clarity. (In the web version C1,1(4) motif hydrogen bonds in blue, C1,1(11) motif hydrogen bonds in green and other hydrogen bonds in red.)

In TE 3-benzoylpyridine (TE3) co-crystal the ratio of TE to 3-benzoylpyridine (3) is 1:2. The 3benzoylpyridine molecules are hydrogen bonded to both arms of the TE molecule in a second level D2,2(12) motif (Fig. 2a) containing the pyridine-amine synthon. The assembly is very symmetrical, but the symmetry is not crystallographic on a larger scale. There are weak aromatic $\mathrm{C}-\mathrm{H} \cdots \mathrm{O}=\mathrm{C}$ hydrogen bonds between adjacent 3-benzoylpyridine molecules as well as from the $\mathrm{C}=\mathrm{O}$ of $\mathrm{TE}$ to the 3-benzoylpyridine molecules. A weak $\mathrm{C}-\mathrm{H} \cdots \mathrm{S}=\mathrm{C}$ hydrogen bond strengthens the pyridine-amine hydrogen bond. If all the weak hydrogen bonds are taken into account the molecules build up chains (Fig. 2b) that elongate in the direction of the crystallographic a-axis. 

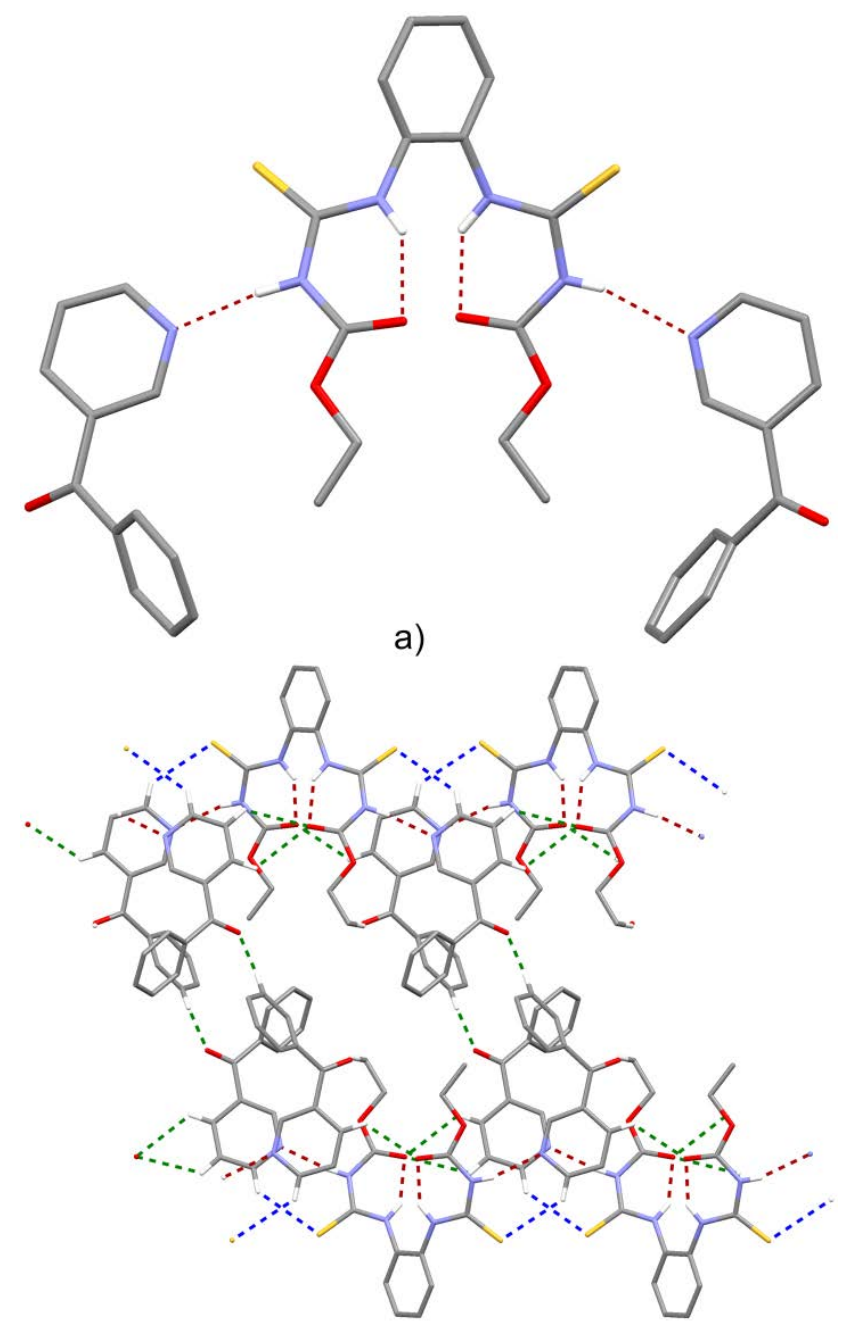

b)

Figure 2. a) Strong hydrogen bonding and b) the weakly hydrogen bonded chains in the 3-benzoylpyridine (TE3) cocrystal with non-hydrogen bonding hydrogen atoms removed for clarity. (In the web version strong hydrogen bonds in red, weak $\mathrm{C}-\mathrm{H} \cdots \mathrm{O}=\mathrm{C}$ hydrogen bonds in green and weak $\mathrm{C}-\mathrm{H} \cdots \mathrm{S}=\mathrm{C}$ hydrogen bonds in blue.)

The PXRD patterns measured from the slurry samples, except for the 2-benzoylpyridine, matched well with the calculated powder diffraction patterns of the determined structures (Fig. 3). The reason for the mismatch between the slurry powder and the determined structure of TE2 indicates the formation of another crystal form that, however, did not crystallize as suitably sized and quality single crystals when the slurry sample was used for the single crystal experiments. No single crystals for the TE co-crystal with 4-phenylpyridine (TE4) were acquired, but the PXRD pattern of the slurry sample was of neither 4-phenylpyridine nor any of the known TE forms, indicating the formation of a co-crystal (Fig. 4). Hydrogen bonding wise the co-crystal (TE4) is expected to be similar to the TE co-crystal with 4,4'-bipyridine [5], which only uses one of the pyridine functional groups for hydrogen bonding to TE. The PXRD patterns of these were compared, but they are not similar (Fig. 4). The TE co-crystal with 4,4'-bipyridine, however, has a Z' of 3 and is likely polymorphic, so a similar hydrogen bonding arrangement for TE4, but with different packing, is still likely. 


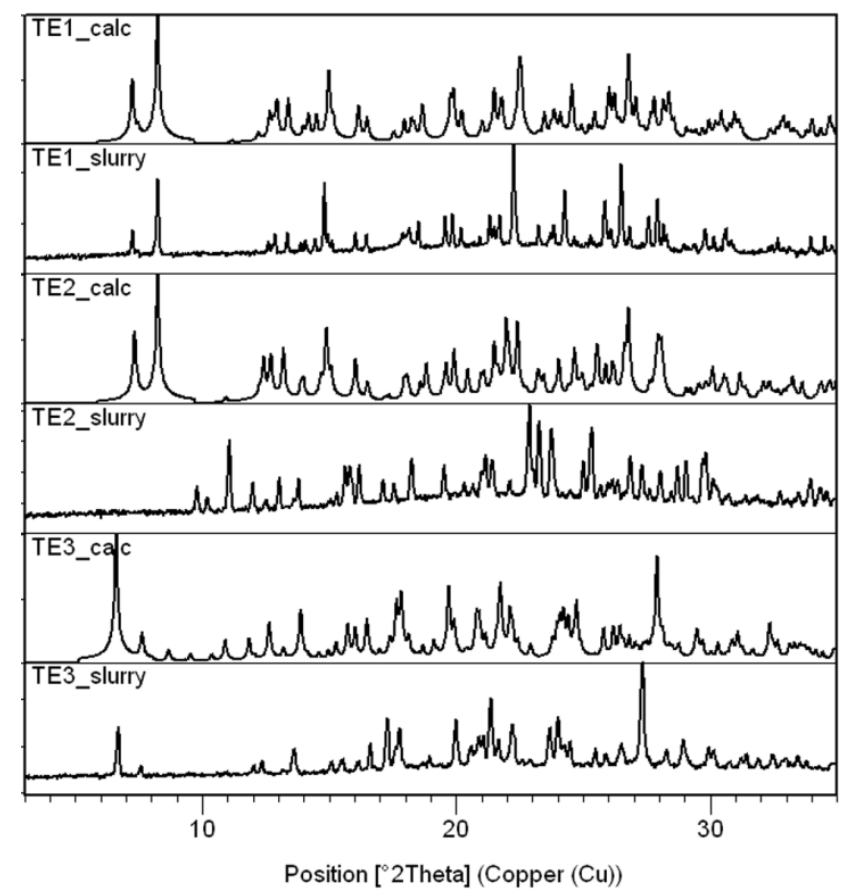

Figure 3. Experimental slurry PXRD patterns and calculated PXRD patterns of co-crystals TE1, TE2 and TE3.

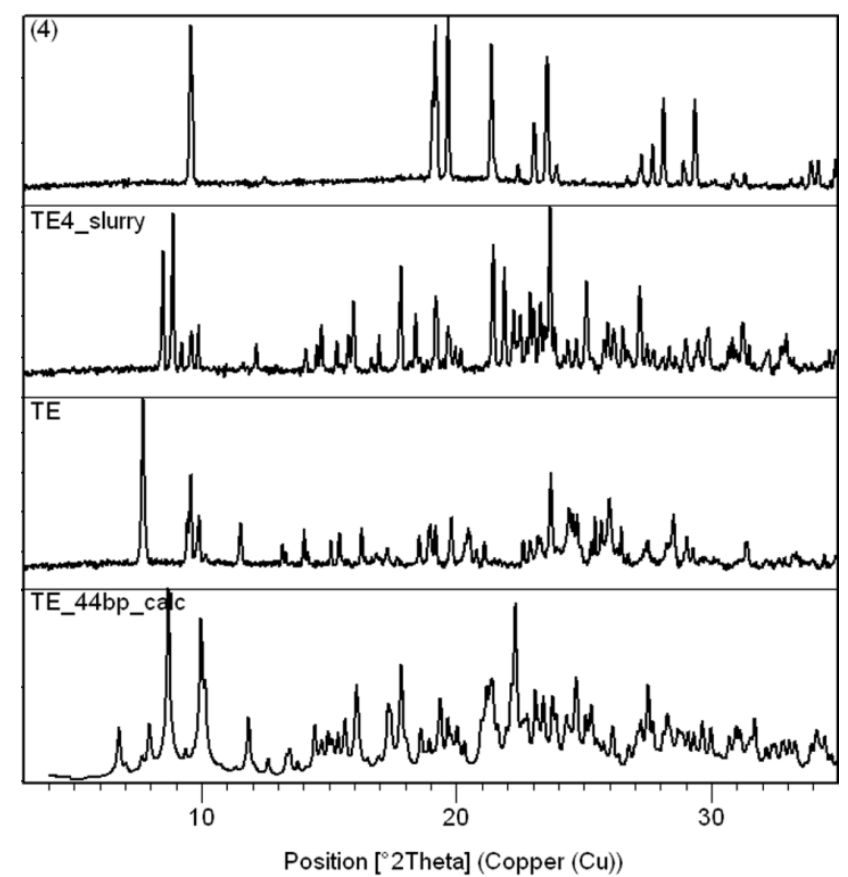

Figure 4. PXRD patterns of 4-phenylpyridine (4), the TE4 slurry sample, TE and the calculated PXRD pattern of the TE co-crystal with 4,4'-bipyridine

\subsection{Biphenyl}

In order to explore the effect of general molecular shape vs. the effect of the $\mathrm{N}-\mathrm{H} \cdots \mathrm{N}$ synthon we crystallized TE with biphenyl. The arrangement (Fig. 5) in the biphenyl co-crystal (TE5), however, is different to that of the 2,2'-bipyridine co-crystal [5] even though the ratio of TE to guest (2:1) is the same. The main hydrogen bonding network of TE molecules is the same with chains of TE connected with a R2,2(8) motif consisting of two $\mathrm{N}-\mathrm{H} \cdots \mathrm{S}=\mathrm{C}$ hydrogen bonds. The chains pack parallel to each other with the aid of $\pi-\pi$ interactions 
between the TE benzene rings with ring centroid to centroid distances of $3.81 \AA$. There are also weak hydrogen bonds from the $\mathrm{C}=\mathrm{O}$ of $\mathrm{TE}$ to one of the benzene ring hydrogen atoms in an adjacent chain. The biphenyl molecules are located between the chains in discrete cavities with no clear interactions to the TE molecules. The PXRD pattern of the slurry sample (Fig. 6) still contained peaks of pure biphenyl (5), but otherwise the pattern matched well with the pattern calculated from the single crystal structure.

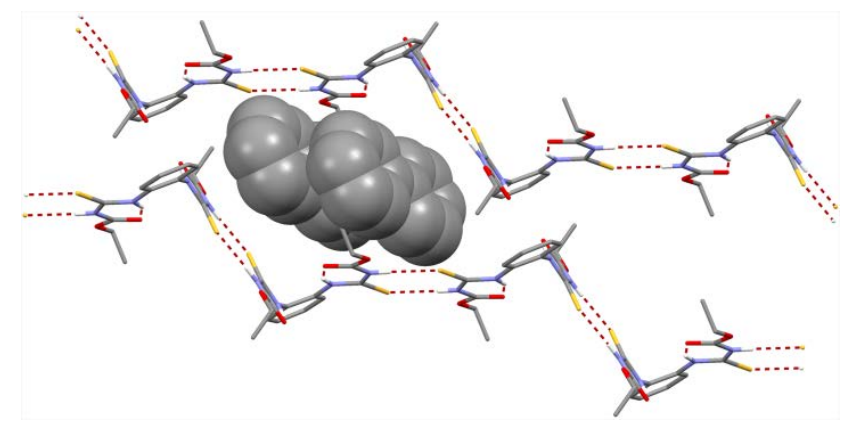

Figure 5. Hydrogen bonding in the biphenyl co-crystal (TE5) with two biphenyl molecules between the chains shown in spacefill style and C-H hydrogen atoms removed for clarity.

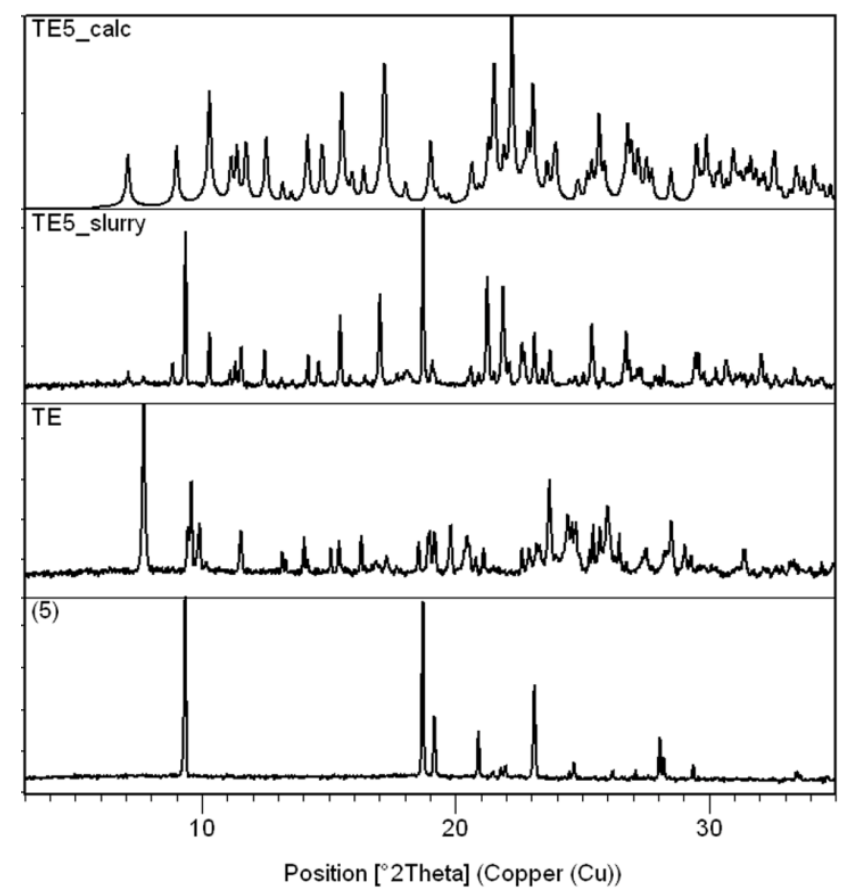

Figure 6. PXRD patterns of biphenyl (5), TE, the TE5 slurry with peaks of (5) visible, and the calculated pattern from the structure.

\section{Conclusions}

Five novel co-crystal forms of TE with a selected group of pyridine containing molecules and a structurally similar biphenyl were found and the crystal structures of four of these solved with single crystal X-ray diffraction. Co-crystal design using the pyridine-amine synthon works well for TE, even though it has other functionalities, which could hinder formation of the desired synthon. The packing of the biphenyl co-crystal, however, could not be predicted even though the shape of the molecule is very similar to 2,2'-bipyridine, for 
which TE builds a packing arrangement containing channels of guest also seen in a number of isomorphic solvates [3]. If no strong hydrogen bonding, like the pyridine amine synthon, to a guest is formed, TE builds chains connected via a R2,2(8) motif of two $\mathrm{N}-\mathrm{H} \cdots \mathrm{S}=\mathrm{C}$ hydrogen bonds. These chains, which are also seen in most of the polymorphs of TE [3], can organize to leave in hydrophobic cavities that the guests can fill. The non-hydrogen bonding guest molecules, like biphenyl, likely act as templates for the packing of the chains. The strong $\mathrm{N}-\mathrm{H} \cdots \mathrm{N}$ synthon breaks the formation of these chains and is a determining factor in the formation of the co-crystal structures of TE. The pyridine-amine synthon was found to be very useful in the design of co-crystals for molecules containing a thioamide group $(-\mathrm{C}(=\mathrm{S})-\mathrm{N}(\mathrm{H})-)$, which is seen in agrochemical and pharmaceutical actives.

\section{Supplementary material}

CCDC 838991 - 838994 contain the supplementary crystallographic data for this paper. These data can be obtained free of charge via http://www.ccdc.cam.ac.uk/conts/retrieving.html (or from the Cambridge Crystallographic Data Centre, 12, Union Road, Cambridge CB2 1EZ, UK; fax: +44 1223 336033).

\section{Acknowledgements}

We would like to thank the Academy of Finland (proj. no. 116503) and the University of Jyväskylä for funding this work.

\section{Notes and references}

[1] P. Wishweshwar, J.A. McMahon and M.J Zaworotko, Crystal Engineering of Pharmaceutical Co-crystals in: E.R.T Tiekink and J.J. Vittal (Ed.), Frontiers in Crystal Engineering, John Wiley \& Sons, England, 2006, p. 25-46.

[2] G.R. Desiraju, Angew. Chem. Int. Ed. Eng. 34 (1995), 2311. doi:10.1002/anie.199523111.

[3] E. Nauha, A. Ojala, M. Nissinen, H. Saxell, CrystEngComm 13 (2011), 4956. doi: 10.1039/C1CE05077J.

[4] E. Nauha, H. Saxell, M. Nissinen, E. Kolehmainen, A. Schäfer, R. Schlecker, CrystEngComm 11 (2009), 2536, doi:10.1039/b905511h.

[5] E. Nauha, E. Kolehmainen, M. Nissinen, CrystEngComm, DOI:10.1039/C1CE05730H.

[6] B. Piotrkowska, A. Wasilewska, M. Gdaniec, T. Polonski, CrystEngComm 10 (2008), 1421.

[7] C. A. Ellis, M. A. Miller, J. Spencer, J. Zukerman-Schpector, E. R. T. Tiekink, CrystEngComm 11 (2009), 1352.

[8] PANalytical B.V., 2.2b, (2006).

[9] Z. Otwinowski, D. Borek, W. Majewski, W. Minor, Acta Cryst. A59 (2003), 228, doi:10.1107/S0108767303005488.

[10] G.M. Sheldrick, Acta Cryst. A64 (2008), 112.

[11] C. F. Macrae, P. R. Edgington, P. McCabe, E. Pidcock, G. P. Shields, R. Taylor, M. Towler, J. van de Streek, J. Appl. Cryst. 39 (2006), 453, doi: 10.1107/S002188980600731X.

[12] M. C. Etter, J. C. MacDonald, Acta Cryst B46 (1990), 256; J. Bernstein, R. E. Davis, L. Shimoni, N-L. Chung, Angew. Chem. Int. Ed. Engl. 34 (1995), 1555. 